\title{
Measuring Equilibrium Real Interest Rates: What can we learn from yields on indexed bonds?
}

\author{
Antulio N. Bomfim* \\ Federal Reserve Board
}

July 30, 2001

\begin{abstract}
What does the level of the real interest rates tell us about where the economy, or one's portfolio, is headed? The answer to this question depends on one's estimate of the "equilibrium" value of real interest rates, a measure that is unfortunately not directly observed in the market place. In this paper, I provide a brief overview of some of the existing approaches to defining and measuring equilibrium real rates and introduce a novel method based on yields on the U.S. Treasury's inflation-indexed securities (TIIS). I discuss a simple framework for analyzing TIIS yields and illustrate how to use them to gauge the stance of monetary policy and overall economic prospects.
\end{abstract}

JEL Classification: E43, G12, E52

Keywords: inflation-indexed securities, forward rates, risk premium, monetary policy.

* Monetary and Financial Market Analysis, Mail Stop 74, Division of Monetary Affairs, Federal Reserve Board, Washington, DC, 20551; Email: abomfim@frb.gov, Fax: (202) 452-2301, Tel.: (202) 736-5619. I thank William English and Brian Sack for comments and Joseph Rosenberg for excellent research assistance. The opinions expressed in this paper are not necessarily shared by the Board of Governors of the Federal Reserve System or any members of its staff. 


\section{Introduction}

Early in the summer of 2001, the Federal Reserve's target for the federal funds rate, the main monetary policy instrument in the United States, stood at 4 percent. Taking into account recent inflation experience in the U.S., the real federal funds rate was likely in the vicinity of $2-1 / 2$ percent. What does that tell us about the stance of monetary policy at that point in time? Was policy too tight? Too easy? More generally, and likely of more immediate concern for most people, what does the level of the real federal funds rate tell us about where the economy, or the performance of one's portfolio, is headed?

Based only on the information provided thus far, the best answer to the above questions is a definite "I don't know." The real federal funds rate tells us only part of the story about monetary policy and the economy. In principle, what matters for assessing the stance of monetary policy - or how that policy stance will affect the economy down the road - is not just the level of the real fed funds rate, but how far that level is from its "equilibrium" value. Of course, this insight is not new, and can be traced back at least all the way to Wicksell (1898). What is new, and potentially interesting, are some recent ways of defining and estimating equilibrium real interest rates, which, after all, cannot be observed directly in the market place. In this paper, I provide a brief overview of some of the existing approaches to defining and measuring equilibrium real rates - section 2 - and then introduce a novel way of using financial market data to get a direct proxy for the equilibrium real rate. In particular, I describe a method for measuring equilibrium real interest rates from observed yields on the U.S. Treasury's inflation-indexed securities (TIIS). A simple framework for analyzing TIIS yields is presented in section 3. Section 4 discusses the TIIS-implied equilibrium real rate measure, illustrating how TIIS yields can be used to gauge the stance of monetary 
policy. Section 5 presents some final remarks and concludes.

\section{Measuring Equilibrium Real Interest Rates}

"Equilibrium real interest rates" can mean different things to different peopleor different things to the same person depending on the context. For the purposes of this paper, my equilibrium notion corresponds to the intermediaterun dynamics of the economy, a time frame that seems most relevant both for the conduct of monetary policy and for the decisions of individual investors. As such, by equilibrium real rate I don't mean that interest rate level that will clear financial and goods markets today, a short-run notion of equilibrium, nor do I mean the level of interest rates that would prevail if the economy were on its long-run equilibrium path, a horizon that might be too far removed to matter for most decision makers.

In general terms, the equilibrium measures described below can be thought of as corresponding to the level of interest rates that would prevail after ongoing temporary imbalances in the economy - those that are expected to dissipate over the intermediate run-work themselves through. Thus, given the current state of the world, which reflects both shorter- and longer-lived "shocks" to the economy, the equilibrium concept I am working with abstracts from the former while focusing only on the more persistent components of economic fluctuations. As a result, it should also be noted that, the equilibrium real rate that emerges from my analysis is not to be interpreted as a simple prescription for monetary policy. Indeed, the very existence of short-term imbalances, which, by construction, are not captured by the equilibrium real rate, may well lead monetary policymakers to temporarily set the intended funds rate at a level consistent with a non-zero spread between actual and equilibrium real rates. 


\subsection{Approaches to Measuring Equilibrium Interest Rates}

Existing approaches for measuring equilibrium real interest rates can be largely grouped under three main headings. Traditional financial-marketbased approaches implicitly attempt to extract information about the (unobserved) equilibrium real rate from observed spreads between short- and long-term interest rates. Model-based approaches tend to rely on elaborate econometric models, and statistics-based methods typically focus on one or two key economic relationships.

Traditional financial-market-based approaches. Financial market participants and researchers alike commonly use the spread between short- and long-term interest rates as a way to gauge the stance of monetary policy and size up the economic outlook. ${ }^{1}$ One possible interpretation for such a practice, suggested by Bernanke and Blinder (1992) and Laurent (1988), is the notion that longer-term interest rates embed market participants' best forecasts of where short-term rates are likely to go in the future, which presumably should be related their (unobserved) equilibrium level. Thus, the yield curve steepens as short-term interest rates are perceived to be below their equilibrium levels and flattens when the reverse is true.

While the term-structure spread approach has the advantage of being relatively free from the assumptions that go into complex econometric models, it has one major drawback: Long rates may rise and fall relative to short rates for reasons other than a changing differential between actual and equilibrium short-term interest rates. For instance, rising concerns about inflation may lead to higher long-term rates even if underlying equilibrium real rates are relatively unchanged. Thus, not only do term structure spreads provide only an indirect way to gauge the difference between actual and equilibrium

\footnotetext{
${ }^{1}$ See, for instance, Estrella and Mishkin (1998) and the references therein.
} 
real rates, but they require careful analysis of the sources of movements in long-term rates.

Model-based approaches. Model-based measures of the equilibrium real rate are an attempt to overcome the limitations of the term-structure-spread approach. Given an economic model, one can derive direct measures of equilibrium real interest rates and compare the model-implied equilibrium series to observed interest rates. For instance, Bomfim (1997) used the MIT-PennSSRC (MPS) model of the U.S. economy, which was then housed and maintained at the Federal Reserve Board, to obtain an equilibrium series for the federal funds rate. That analysis suggested that the spread between actual and equilibrium federal funds rates tended to outperform term structure spreads as predictors of a wide range of macroeconomic indicators.

Model-based approaches have another advantage over simple methods based on spreads between short- and long-term yields: They allow for the systematic accounting of the sources of movements in equilibrium real rates, as in Bomfim's (1998) analysis of the Federal Reserve's FRB/US model of the U.S. economy. Nonetheless, model-implied measures of equilibrium real rates also have their own limitations. First, structural models that are able to generate "realistic-looking" time series for equilibrium real rates tend to be fairly large and complex systems of equations. Second, and unsurprisingly, a model's estimate of an equilibrium interest rate measure is only as good as the model itself, depending heavily on the economic assumptions of the model builders and how the model parses out economic shocks into persistent and temporary disturbances.

Statistics-Based Approaches. The complexity of large structural models has motivated the development of simpler methods for measuring equilibrium real rates. These range from computing simple historical averages of real interest rates - under the assumption that, on average, actual rates are at 
or near their equilibrium values - to more elaborate techniques based the estimation of small-scale, reduced-form, systems. An example of the latter is the work of Laubach and Williams (2001), who used the Kalman filter and a two-equation system relating U.S. GDP behavior to short-term real interest rates to generate an equilibrium real federal funds rate series.

To sum up, each of the approaches discussed above has its strengths and weaknesses. Some are more direct measures of equilibrium real rates than others, and they all vary in the extent to which they depend on the theoretical priors of the analyst.

\section{Treasury Inflation-Indexed Securities}

Yields on the U.S. Treasury's inflation-indexed securities (TIIS) provide a novel way to estimate equilibrium real rates from observed financial market prices. Although the TIIS-based approach generally follows the spirit of traditional financial market-based methods for measuring equilibrium interest rates, it has the advantage that it is not distorted by inflation expectations or inflation risk premiums. Before describing this approach, however, I shall lay out a simple framework for analyzing TIIS yields.

\subsection{Understanding TIIS Cash Flows}

Unlike conventional bonds, which make fixed coupon payments until maturity, inflation-indexed securities issued by the U.S. Treasury make coupon payments that are tied to underlying inflation. ${ }^{2}$ In particular, although a TIIS has a fixed coupon rate, its face value is adjusted periodically for inflation, and we can write the payment stream of a TIIS that matures $n$ periods

\footnotetext{
${ }^{2}$ Wilcox (1998) discusses TIISs in detail.
} 
from now as

$$
V_{t}^{(n)}=\left[C\left(1+\pi_{t}\right), C\left(1+\pi_{t}\right)\left(1+\pi_{t+1}\right), \ldots,(1+C) \Pi_{i=0}^{n-1}\left(1+\pi_{t+i}\right)\right]
$$

where $C$ is the bond's coupon rate, and $\pi_{t+i}$ is the inflation rate between coupon payment dates $t+i-1$ and $t+i$. The first element of $V^{(n)}$ denotes the first coupon payment, which will be received one period from now, the second element corresponds to the second payment, and so on. For ease of exposition, I assume throughout this paper that the initial face value of the bond is $\$ 1$.

\subsection{A Simple Analytical Framework for TIIS yields}

I shall adapt the linearized expectations framework described by Shiller (1979), which was developed for the analysis of conventional bonds, to the analysis of inflation-indexed bonds. The first significant difference regarding the analysis of conventional and indexed bonds relates to the treatment of future inflation, which figures explicitly in the cash flows of indexed bonds but only implicitly — as the expected inflation component of the bond's yield —in the payment stream of conventional bonds.

Inflation makes the future cash flows of indexed bonds uncertain and thus requires us to take a stand regarding the terms involving $\pi_{t+j}$, for $j>0$, in equation (1). Below, I shall make the simplifying assumption that investors expect inflation to remain constant during the life of the bond. Such an assumption might not be too far from reality if, for instance, investors expect that monetary policymakers will continue to endeavor to keep inflation at its currently low level. ${ }^{3}$

\footnotetext{
${ }^{3}$ In the next section, I examine this assumption more closely.
} 
Given an assumed rate of inflation of $\bar{\pi}$ between coupon payment dates, we can write the present value of the indexed bond's cash flow, discounted at the nominal interest rate $R_{t}^{(n)}$, as:

$$
P V\left(V_{t}^{(n)}, R_{t}^{(n)}\right)=\frac{C(1+\bar{\pi})}{\left(1+R_{t}^{(n)}\right)}+\frac{C(1+\bar{\pi})^{2}}{\left(1+R_{t}^{(n)}\right)^{2}}+\ldots+\frac{(1+C)(1+\bar{\pi})^{n}}{\left(1+R_{t}^{(n)}\right)^{n}}
$$

In a no arbitrage equilibrium, $R_{t}^{(n)}$ should be such that the market price of the n-period indexed bond, $P_{t}^{(n)}$, coincides with with $P V\left(V_{t}^{(n)}, R_{t}^{(n)}\right)$. Thus, simplifying the above expression and enforcing the no-arbitrage condition, we have:

$$
P_{t}^{(n)}=\frac{C(1+\bar{\pi})}{R_{t}^{(n)}-\bar{\pi}}+\frac{R_{t}^{(n)}-\bar{\pi}-C(1+\bar{\pi})}{\left(R_{t}^{(n)}-\bar{\pi}\right)\left[\left(1+R_{t}^{(n)}\right) /(1+\bar{\pi})\right]^{n}}
$$

which gives a simple pricing relationship for the n-period indexed bond. Given that we are assuming the the bond is valued at par, and has an initial face value of $\$ 1$, the no-arbitrage condition requires that

$$
R_{t}^{(n)}-\bar{\pi}=C(1+\bar{\pi})
$$

For our purposes, it will prove convenient to simplify equation (3) by noting that $\left[\frac{1+R_{t}^{(n)}}{1+\bar{\pi}}\right]$, which appears in the denominator of $(3)$, is approximately equal to $\left(1+R_{t}^{(n)}-\bar{\pi}\right)$. This allows us to write the following approximation to the market price of the indexed bond:

$$
\hat{P}_{t}^{(n)}=\frac{C(1+\bar{\pi})}{R_{t}^{(n)}-\bar{\pi}}+\frac{R_{t}^{(n)}-\bar{\pi}-C(1+\bar{\pi})}{\left(R_{t}^{(n)}-\bar{\pi}\right)\left(1+R_{t}^{(n)}-\bar{\pi}\right)^{n}}
$$

With regard to the quality of the above approximation, I should note, first, that, when the bond is selling at par, (5) reduces to (3) exactly. Second, 
(5) is a close approximation to (3) when the bond is selling at close to par because the numerator of the second term of the pricing relationship will then be close to zero. ${ }^{4}$

If we now define,

$$
\begin{aligned}
y_{t}^{(n)} & \equiv R_{t}^{(n)}-\bar{\pi} \\
c & \equiv C(1+\bar{\pi})
\end{aligned}
$$

we can write the following expression for the price of an inflation-indexed bond

$$
P_{t}^{(n)}=\frac{c}{y_{t}^{(n)}}+\frac{y_{t}^{(n)}-c}{y_{t}^{(n)}\left(1+y_{t}^{(n)}\right)^{n}}
$$

which is exactly analogous to the expression written by Shiller (1979) for the price of conventional bonds. In particular, we can think of $y_{t}^{(n)}$ as the yield to maturity of the n-period inflation-indexed bond. Furthermore, if we think of $R_{t}^{(n)}$ as the yield to maturity on a conventional bond, we arrive at the intuitive result that the difference between yields on conventional and inflation-indexed securities provides a reading on investors' expectations of inflation going forward. ${ }^{5}$

Taking equation (8) as my point of departure, I will now derive a simple expression for indexed bond yields. First, it is easy to see that we can write the one-period holding return associated with a recently issued n-period bond

\footnotetext{
${ }^{4}$ Historically, market prices for ten-year TIISs have ranged from 4 percent below par to nearly 6 percent above par. To assess the quality of the approximation embedded in equation (5), consider a ten-year TIIS priced at 8 percent below par. Even for such an outsized difference between the face value and market price of the bond, the approximation error implied by (5) is still very small: The price implied by (5) is less than 1 percent below that given by (3).

${ }^{5}$ Sack $(2000)$ examines this issue in detail.
} 
as

$$
H_{t}^{(n)}=\frac{P_{t+1}^{(n-1)}+c-P_{t}^{(n)}}{P_{t}^{(n)}}
$$

which simply says that the return from holding the n-period bond from $t$ to $t+1$ equals to the net gain from holding the bond during that period divided by the purchase price of the bond, where the net gain is the sum of the coupon payment received at $t+1$ and the capital gain/loss incurred on the sale of the bond.

Following Shiller (1979), I insert (8) into (9) and linearize the resulting expression around $y_{t}^{(n)}=y_{t}^{(n-1)}=c$. This leads to the following linear approximation to the one-period holding return:

$$
\hat{H}_{t}^{(n)}=\frac{y_{t}^{(n)}-\lambda_{n} y_{t+1}^{(n-1)}}{1-\lambda_{n}}
$$

where $\lambda_{n} \equiv \frac{\lambda\left(1-\lambda^{n-1}\right)}{1-\lambda^{n}}$, and $\lambda \equiv 1 /(1+c)$.

Equation (10) is an ordinary difference equation in $y_{t}^{(n)}$. Here I should note that, up until now, I have derived the results essentially without having to assume any particular model for the evolution of interest rates. To find a particular solution to (10), however, I shall now add some economic content to the framework. Accordingly, I assume that the expected one-period holding return for the n-period bond is a function of both the short-term interest rate, $y_{t}^{(1)}$ —or the yield on a one-period bond - and a constant "risk premium"

$$
E_{t} H_{t}^{(n)}=y_{t}^{(1)}+\phi^{(n)}
$$

where $E_{t}$ denotes an expectation based on information available at time $t$, and the risk premium $\phi^{(n)}$ has both a term- and a convexity-premium component, with $\phi^{(1)}=0$.

Given a terminal condition that guarantees that the one-period return on 
holding a one-period bond equals its yield to maturity:

$$
\hat{H}_{t+n-1}^{(1)}=y_{t+n-1}^{(1)}
$$

we obtain the following solution to (10):

$$
y_{t}^{(n)}=\frac{1-\lambda}{1-\lambda^{n}} \sum_{j=0}^{n-1} \lambda^{j} E_{t} y_{t+j}^{(1)}+\Phi^{(n)}
$$

where $\Phi^{(n)} \equiv \frac{1-\lambda}{1-\lambda^{n}} \sum_{j=0}^{n-1} \lambda^{j} \phi^{(n-j)}$ is the risk premium associated with the indexed bond maturing $n$ periods from now.

The above equation is exactly analogous to Shiller (1979) 's linearized framework for conventional bonds, except that $y_{t}^{(n)}$, defined as $R_{t}^{(n)}-\bar{\pi}$, is a real interest rate, whereas Shiller's specification dealt only with $R_{t}^{(n)}$, which is a nominal interest rate.

\section{TIIS-Implied Equilibrium Real Rates}

The above framework suggests that TIIS yields can be thought of primarily as reflecting market participants' expectations of future short-term real interest rates. As a result, long-dated TIIS yields should reflect investors' views of where real short rates will be after temporary macroeconomic imbalances have worked themselves through. Nonetheless, simply interpreting TIIS yields as the market's perception of the equilibrium real rate could be misleading because - as indicated in equation (13) —investors discount cash flows in the more distant future more heavily than cash flows in the near term. Thus, even long-dated TIIS yields can be more importantly affected by expectations of where real short-term interest rates might be in the very near future than by forecasts of where those rates are expected to settle down 
in the medium to long term.

One possible approach to circumvent the relatively short horizons embedded in TIIS yields is to focus only on the long end of the forward interest rate curve. For instance, one might look at the forward rate implied by ten- and thirty-year TIIS. Given equation (13), and following Shiller, Campbell, and Schoenholtz's (1983) analysis of conventional bonds, we can write a linear approximation to the n-period ahead, m-period forward rate, $f_{t}^{n, m}$, as

$$
f_{t}^{n, m}=\frac{D^{(m+n)} y_{t}^{(m+n)}-D^{(n)} y_{t}^{(n)}}{D^{(m+n)}-D^{(n)}}
$$

where $D^{(j)}$ denotes the Macaulay duration of a j-period indexed bond, defined as $-\frac{\partial P_{t}^{(n)}}{\partial y_{t}^{(n)}} \frac{1}{P_{t}^{(n)}} \cdot 6$

Embedded in equation (14) are market participants' forecasts of where short-run real rates should be, on average, $n$ to $n+m$ periods from now. In particular, given (14), we can write

$$
f_{t}^{n, m}=\sum_{j=0}^{m-1} w_{j} E_{t} y_{t+n+j}-\left[\frac{D^{(m+n)} \Phi^{(m+n)}-D^{(n)} \Phi^{(n)}}{D^{(m+n)}-D^{(n)}}\right]
$$

where $w_{j} \equiv \frac{(1-\lambda) \lambda^{j}}{\lambda^{n}\left(1-\lambda^{m}\right)}$, and the term is square brackets in the above expression is the forward premium associated with the n-step-ahead m-period forward rate.

If we set $n$ at 10 years and $m$ at 20 years in equation (16), the corresponding forward rate would reflect market participants' expectations of average

\footnotetext{
${ }^{6}$ As shown by Shiller et al. (1983), as $c$ approaches zero, the bonds become discount bonds, and we obtain the usual expression for forward rates

$$
f_{t}^{n, m}=\frac{(m+n) y_{t}^{(m+n)}-n y_{t}^{(n)}}{m}
$$


short-term real interest rates 20 to 30 years from now, given yields on tenand thirty-year coupon-bearing inflation-indexed bonds. Under the assumption that any transitory shocks will have run their course over the coming ten years, this forward rate should embed an estimate of the medium-term equilibrium value of real short-term Treasury yields, which will be termed $y_{t}^{*}$ in what follows. If we assume further that the term and convexity premiums embedded in $\Phi^{(n)}$ and $\Phi^{(n+m)}$ make the associated forward premium roughly zero, we arrive at: ${ }^{7}$

$$
y_{t}^{*}=\frac{D^{(30)} y_{t}^{(30)}-D^{(10)} y_{t}^{(10)}}{D^{(30)}-D^{(10)}}
$$

Thus, we now have a framework that allows us to convert observed yields on inflation-indexed securities, $y_{t}^{(n)}$, into a market-implied measure of equilibrium real interest rates.

\subsection{Data and Results}

The U.S Treasury started issuing inflation-indexed securities with an inaugural offering of ten-year TIISs in January 1997. The first five-year TIISs were also issued in 1997, and the first ever offering of thirty-year TIISs took place in 1998. These facts dictate the beginning of the sample used in this paper, which includes daily yields on ten- and thirty-year TIIS from 1998 to $2001 .^{8}$

My focus is on "on-the-run" TIIS yields, which are yields on most recently issued securities. ${ }^{9}$ On-the-run yields have two main advantages over yields on

\footnotetext{
${ }^{7}$ The assumption of a near-zero forward premium requires the term structure of risk premiums, $\Phi^{(n)}$, to be sufficiently downward sloping between the ten- and thirty-year maturities. I examine below the sensitivity of the results to this assumption.

${ }^{8}$ Five-year TIIS have not been issued since late 1997 . They transact at prices substantially away from par and are thus not included in the dataset.

${ }^{9}$ The data are quarterly averages of end-of-day TIIS yields from Telerate.
} 
older securities: First, on-the-run status is typically associated with greater liquidity, and thus observed market prices are more likely to represent quotes at which transactions actually took place. Second, the analytical framework described in the previous section is intended for securities that transact at or close to par, an attribute that is more likely to be found among the most recently issued instruments.

The first step in applying the analytical framework described in the previous section to derive a measure of $y_{t}^{*}$ from TIIS yields is to compute the duration of the underlying securities. As suggested by equation (1), the duration of an inflation-indexed bond is not known in advance as it will depend on realized inflation during the life of the bond. To deal with this complication, I follow an approach that is consistent with the linearization scheme outlined in section 3 , assuming a constant rate of inflation, $\bar{\pi}$, over the life of the bond. I experimented with various values for $\bar{\pi}$, ranging from annual inflation rates of 1 percent to 4 percent. With such a range of values, the estimated duration of ten-year TIISs hovered around just above 8 years, and that of thirty-year TIISs was in the vicinity of 18 years. On the whole, as reported below, the equilibrium real rate series derived from TIIS were robust to plausible variations in assumed future inflation.

The TIIS-implied equilibrium real rate series. Figure 1 shows the equilibrium real interest rate series obtained by using ten- and thirty-year TIIS yields in the context of equation (14). By this measure, equilibrium real rates have been relatively stable in recent years, ranging from 3.6 percent in early 1998 to around 4 percent in the second half of 1999. The peak in TIIS-implied equilibrium real rate coincides with the surge in economic activity in the second half of 1999 and early 2000, a period when the markets apparently marked up their estimates of the longer-run equilibrium level of real interest rates. 
The figure also shows on-the-run yields on ten- and thirty-year TIISs, indicating that, in late 2000 and early 2001, both the ten- and thirty-year TIIS yields were below the implied equilibrium short-term real rate. Thus, if the various premiums are roughly offsetting, market participants were expecting the short-term real rate to dip below its equilibrium level in the near term, which was consistent with expectations, at the time, of a temporary slowing U.S. economy.

\subsection{Sensitivity Analysis}

I perform below a battery of sensitivity tests regarding the main assumptions made thus far.

Sensitivity to risk premium assumptions. As noted above, equation (17) is based on the assumption that the forward premium associated with the forward rate implied by ten- and thirty-year TIIS yields is zero. Although such an assumption is consistent with the strongest version of the expectations hypothesis of the term structure of interest rates, I have chosen to justify it by postulating that the convexity premium component of longer-dated yields is such that the term structure of risk premiums, $\Phi^{(n)}$, is negatively sloped between the ten- and thirty-year maturities.

Table 1 summarizes how alternative assumptions on the level and shape of the term structure of risk premiums affect the size of the forward premium implied by ten- and thirty year TIIS yields. The numbers shown in column 1 show that, when the risk premium associated with the thirty-year TIIS is about half of that on the ten-year TIIS, the forward premium is indeed very close to zero. For instance, for $\Phi^{(10)}=50$ basis points - which is roughly the estimated risk premium reported by Brayton and Tinsley (1996) for conven-

tional (non-inflation-indexed) ten-year Treasuries $-\Phi^{(30)}$ would have to be 
about 25 basis points to keep the forward premium close to zero, given my estimates of the durations of the ten- and thirty-year inflation-indexed instruments. One may argue, however, that the ten-year TIIS risk premium is likely below the risk premium on conventional ten-year Treasuries given that theory suggests an inflation risk premium is embedded in the later but not in the former. ${ }^{10}$ Accordingly, in the second row of column 1, I arbitrarily set $\Phi^{(10)}$ at 30 basis points, and, not surprisingly, the results are still consistent with the zero forward premium assumption made above.

The numbers in the second column of Table 1 show forward premium estimates that would be consistent with a flat term structure of risk premiums between the ten- and thirty-year maturities: Under such circumstances, the corresponding forward premium would be of the same order of magnitude as $\Phi^{(10)}$, suggesting that equation (17) would overestimate the equilibrium real rate by 30 to 50 basis points depending on one's estimate of $\Phi^{(10)}$. Nonetheless, the assumption of a flat term structure of risk premiums at the long end of the yield curve is contradicted by the empirical observation that the long end of the forward rate curve is generally downward-sloping (see, e.g., Brown and Schaefer, 2000). Thus, for the given values of $\Phi^{(10)}$, I view the forward premium values in column 2 of Table 2 as being too high to be empirically plausible. Still, uncertainty about the slope of the forward premium curve translates into some uncertainty about the precise level of the TIIS-implied equilibrium real rate, although, for relatively stable forward premiums, it would still be the case that changes in the TIIS-implied measure should correspond closely to changes in market participants' assessments of the equilibrium level of short-term real interest rates. ${ }^{11}$

\footnotetext{
${ }^{10} \mathrm{~A}$ counter-argument would be that TIIS yields incorporate a higher illiquidity premium than conventional Treasuries, at least partly offsetting the inflation risk premium effect.

${ }^{11}$ The question about the size of the downward tilt in the forward premium curve goes beyond the scope of this paper and is the subject of ongoing research.
} 
Sensitivity to inflation assumption. The results reported thus far assume that inflation will run at 3 percent over the next thirty years, which is about the average core consumer price inflation since 1990. Table 2 shows alternative time series for $y^{*}$, based on different values for $\bar{\pi}$. In particular, I reset $\bar{\pi}$ at 1, 2, and 4 percent, recomputing the implied equilibrium real rate each time. The results in the table show little sensitivity to the particular value of $\bar{\pi}$ used.

\subsection{Gauging the Stance of Monetary Policy}

By construction, the TIIS-implied equilibrium real rate measure corresponds to a Treasury borrowing rate and thus can be thought of as an equilibrium measure for short-term real Treasury yields. An equilibrium real rate measure that is likely of greater interest to market participants, including monetary policymakers, is the equilibrium value of the real federal funds rate, which corresponds to the main monetary policy instrument in the United States.

One can adjust the TIIS-implied equilibrium real rate for tax and risk premium effects to obtain an estimate of the equilibrium real fed funds rate. The tax effect stems from the fact that interest earned on Treasury securities is tax-exempt at the state level, but earnings in the federal funds market are not. Assuming that investors are taxed at a marginal rate of 11 percent at the state level, which has been roughly the marginal tax rate for New York residents in recent years, I computed a taxable-equivalent equilibrium real rate. After converting the TIIS-implied equilibrium real rate to a money market basis, which is the basis on which the federal funds rate is quoted, I used the following simple expression to arrive at a tax-adjusted equilibrium real rate, $y_{t}^{*, \operatorname{tax}}$ :

$$
y_{t}^{*, \operatorname{tax}}=\frac{y_{t}^{*}+\tau \pi_{t}}{1-\tau}
$$


where $\tau$ is the marginal tax rate at the state level. Equation (18) takes account of the fact that taxes are paid on nominal, rather than real returns.

I adjusted the resulting taxable-equivalent equilibrium real rate further by adding to it the average spread computed over the 1962-2000 period between the taxable-equivalent yield on three-month Treasury bills and the (annualized) federal funds rate. I called the resulting series the TIIS-implied measure of the equilibrium real federal funds rate.

As shown in Figure 2, TIIS yields suggest that the monetary policy easings of 1998 drove the real fed funds rate below its equilibrium, but the tightenings of 1999 and 2000 more than reversed those earlier actions. More recently, while the TIIS-based measure suggests that policy was relatively tight at the end of 2000, the policy easings of the first half of 2001 brought the real funds rate below its medium- to long-term equilibrium.

Sensitivity to tax rate assumption. To assess the sensitivity of the above results to the assumed marginal tax rate, I also performed computations based on marginal tax rates of 5 percent and 17 percent. Under either assumption, the resulting equilibrium real federal funds series were generally less than 10 basis points away from the series based on the 11 percent marginal tax rate.

\section{Concluding Remarks}

This paper showed how yields on the U.S. Treasury's inflation-indexed securities can be used to derive an equilibrium series for short-term real interest rates. In developing an analytical framework for the derivations, I modified the linearized expectations model described by Shiller (1979), which was originally intended for the analysis of conventional (non-indexed) bonds.

I illustrated the usefulness of the TIIS-implied equilibrium real rate series as an economic indicator in two ways. First, I found that movements in the 
TIIS-implied equilibrium real rate series are broadly in line with the performance of the U.S. economy in the past few years, suggesting that market participants marked up their estimates of longer run prospects for the economy during the recent period of exceptionally strong growth. Second, after adjusting the TIIS-implied equilibrium measure for tax and risk premium effects, I showed that the spread between actual and equilibrium real federal funds rates provides a plausible characterization of the stance of monetary policy in recent years.

The methodology described in this paper has several advantages over other approaches to deriving equilibrium real rates. First, because it is directly based on observed financial market prices, the TIIS-implied equilibrium real rate is explicitly forward-looking. Second, the equilibrium real rate derived in this paper is independent of the elaborate assumptions that typically make up the core of sophisticated economic models. Nonetheless, the TIIS-implied equilibrium real rate series has its own limitations. For instance, to convert forward rates into market expectations of equilibrium real rates, one needs estimates of term and convexity premiums associated with indexed-bond yields. It turns out, however, that these premiums are very hard to estimate even for conventional (nominal) yield curves, and uncertainty about their term structure translates into some uncertainty regarding the precise level of the equilibrium real rates computed in this paper. An additional limitation of the TIIS-based approach is the short length of the resulting equilibrium real rate time series. TIIS have not been around for that long, and thus any historical analysis of equilibrium real rates that goes back farther than the late 1990s is essentially impracticable in the framework described in this paper.

Lastly, I should note that an alternative approach to the analytical framework described in this paper would be either to model forward real rates 
directly - for instance, using the methodology introduced by Heath, Jarrow, and Morton (1992) — or to fit observed yields to a relatively simple functional form, as in the paper by Svensson (1994). A significant impediment to taking either approach is the sparseness of the TIIS yield curve, which, other than the original five-year TIIS that were last issued in 1997, effectively is made up of a small cluster of points around the ten-year maturity and an even smaller number of yields close to the thirty-year maturity. 


\section{References}

Bernanke, Ben S., and Alan S. Blinder, 1992, "The Federal Funds Rate and the Channels of Monetary Transmission," American Economic Review, September, 901-21.

Bomfim, Antulio N., 1997, "The Equilibrium Fed Funds Rate and the Indicator Properties of Term-Structure Spreads," Economic Inquiry, October, 830-846.

Bomfim, Antulio N., 1998, "Measuring Equilibrium Real Interest Rates," Manuscript, Federal Reserve Board.

Brayton, Flint, and Peter A. Tinsley (eds.), 1996, "A Guide to FRB/US: A macroeconomic model of the United States," Federal Reserve Board, Finance and Economics Discussion Series \#1996-46.

Brown, Roger H., and Stephen M. Shaefer, 2000, "Why Long-Term Forward Interest Rates (Almost) Always Slope Downwards," Manuscript, London Business School.

Estrella, Arturo, and Frederic S. Mishkin, 1998, "Predicting U.S. Recessions: Financial variables as leading indicators." Review of Economics and Statistics $80,45-62$.

Heath, David, Robert Jarrow, and Andrew Morton, 1992, "Bond Pricing and the Term Structure of Interest Rates," Econometrica 60, 77-106.

Laubach, Thomas, and John C. Williams, 2001, "Measuring the Natural Rate of Interest," Manuscript, Federal Reserve Board.

Laurent, Robert D., "An Interest Rate-Based Indicator of Monetary Policy," Economic Perspectives (Federal Reserve Bank of Chicago), January/February, $3-14$. 
Sack, Brian P., 2000, "Deriving Inflation Expectations from Nominal and Inflation-Indexed Treasury Yields," Journal of Fixed Income 10, 6-17.

Schiller, Robert J., 1979, "The Volatility of Long-Term Interest Rates and Expectations Models of the Term Structure," Journal of Political Economy 87, 1190-1219.

Schiller, Robert J., John Y. Campbell, and Kermit L. Schoenholtz, 1983, "Forward Rates and Future Policy: Interpreting the term structure of interest rates," Brookings Papers on Economic Activity 1, 173-223.

Svensson, Lars E. O., 1994, "Estimating and Interpreting Forward Interest Rates: Sweden 1992-1994," Working Paper 114, International Monetary Fund.

Wicksell, Knut, 1898, Interest and Prices: A study of the causes regulating the value of money, English Translation, London: Macmillan, 1936.

Wilcox, David W., 1998, "The Introduction of Indexed Government Debt in the United States," Journal of Economic Perspectives 12, 219-228. 
Table 1

\section{Effects of Alternative Risk Premium Assumptions} on the Size of the Forward Premium

\begin{tabular}{lcc}
\hline \hline & $\Phi^{(30)}=\Phi^{(10)} / 2$ & $\Phi^{(30)}=\Phi^{(10)}$ \\
\hline$\Phi^{(10)}=0.50$ & 0.05 & 0.50 \\
$\Phi^{(10)}=0.30$ & 0.03 & 0.30 \\
\hline \hline
\end{tabular}

Note. Table entries refer to the forward premium in equation (16) with $n$ set to 10 years and $m$ set to 20 years. 
Table 2

TIIS-Implied Equilibrium Real Interest Rate Series:

Sensitivity to Alternative Assumptions on Inflation

\begin{tabular}{lccccc}
\hline \hline & 1998 & 1999 & 2000 & $2001: \mathrm{Q} 1$ & $2001: \mathrm{Q} 2$ \\
\hline $\bar{\pi}=3$ percent (baseline) & 3.65 & 3.92 & 3.86 & 3.64 & 3.70 \\
$\bar{\pi}=1$ percent & 3.63 & 3.91 & 3.86 & 3.64 & 3.71 \\
$\bar{\pi}=2$ percent & 3.65 & 3.92 & 3.88 & 3.62 & 3.67 \\
$\bar{\pi}=4$ percent & 3.65 & 3.93 & 3.89 & 3.60 & 3.63 \\
\hline \hline
\end{tabular}

Note. Numbers shown are period averages, expressed on an annual basis, and correspond to equilibrium short-term real Treasury yields. 
Figure 1

TIIS-implied Equilibrium Real Rates

TIIS-implied equilibrium real rate

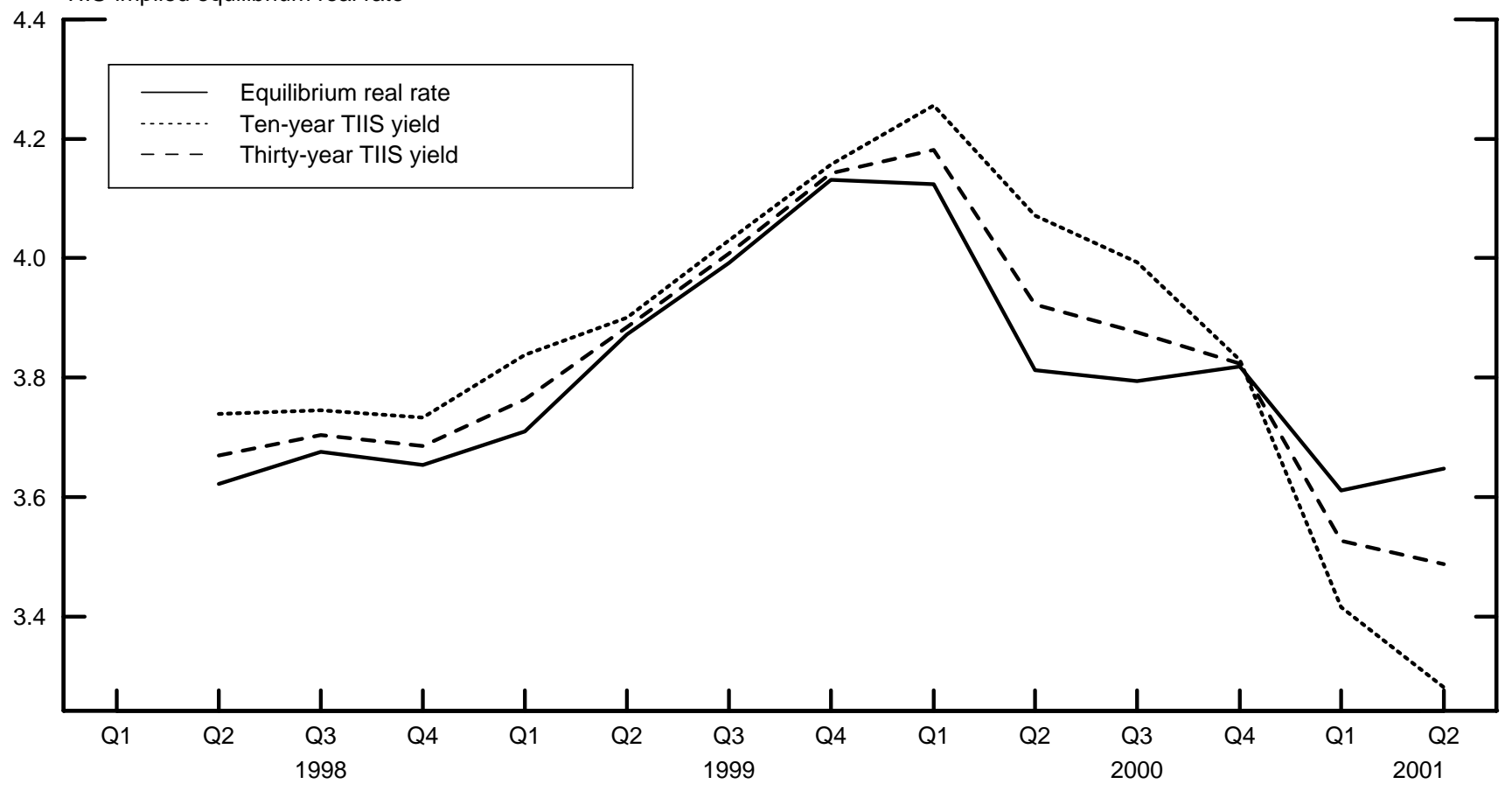


Figure 2

Gauging the Stance of Monetary Policy

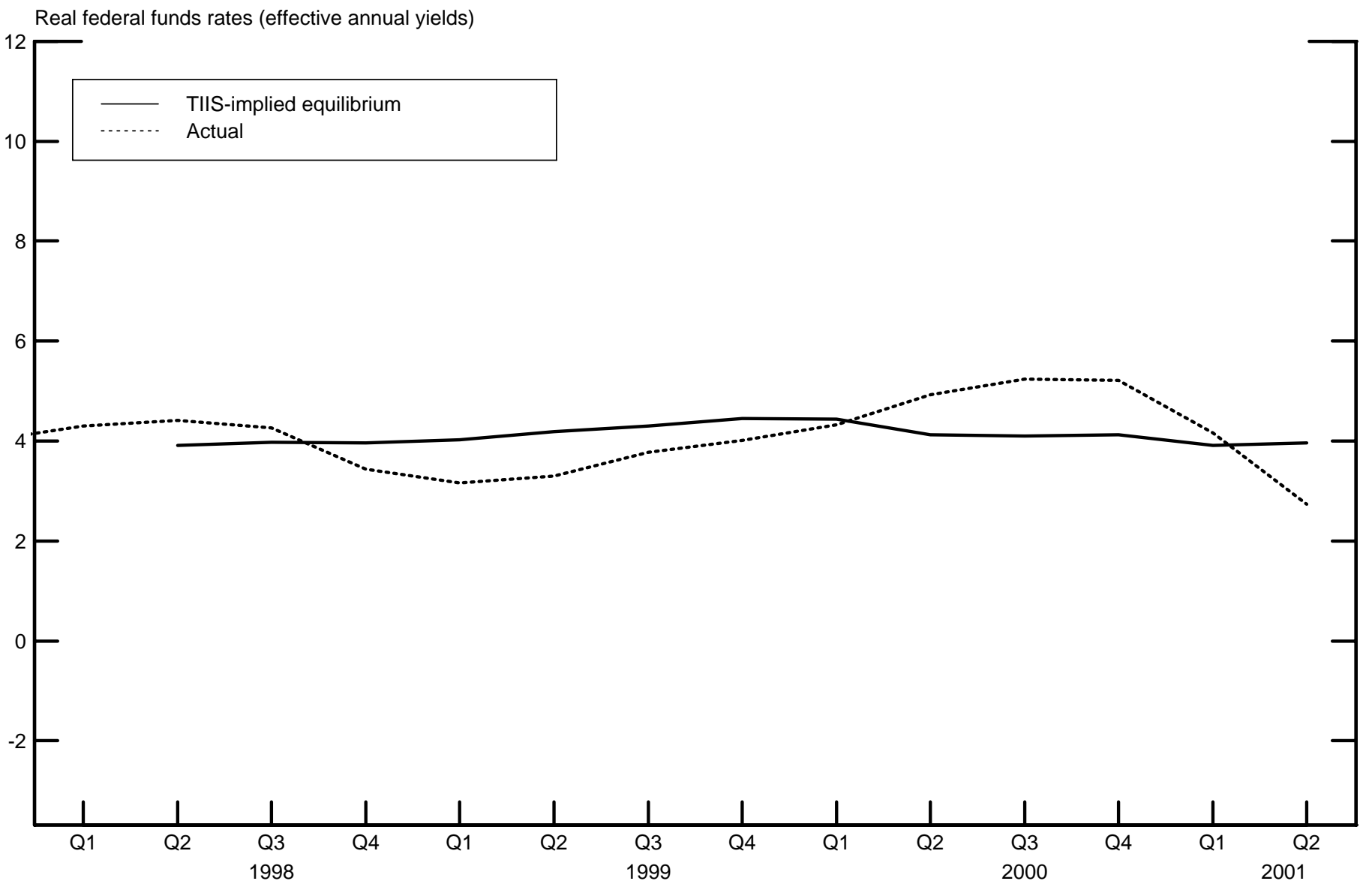

